\title{
CARACTERIZAÇÃO ANATÔMICA E HISTOQUÍMICA DE RAÍZES E FOLHAS DE PLÂNTULAS DE Anacardium occidentale L. (Anacardiaceae) ${ }^{1}$
}

Ana Luísa Lopes Ernesto Reis², Daniele Souza da Silva ${ }^{3}$, Kellen Lagares Ferreira Silva e Davi Borges das Chagas $^{3}$

\begin{abstract}
RESUMO - Anacardium occidentale L. (Anacardiaceae) é uma espécie típica do Cerrado do Brasil Central e possui valor socioeconômico. Objetivou-se caracterizar anatômica e histoquimicamente as raízes e folhas desta espécie em diferentes estádios iniciais de desenvolvimento. Para a caracterização anatômica, as amostras foram fixadas em $\mathrm{FAA}_{50}$, incluídas em parafina e submetidas aos procedimentos usuais para microscopia de campo claro. Foram realizados testes histoquímicos para detecção de lipídios totais, taninos, lignina, amido e terpenoides com grupo carbonila nas folhas, bem como teste para amido nas raízes em cortes frescos. A raiz apresenta epiderme unisseriada, floema com canais secretores e xilema tetrarco. Aos cinco dias após a germinação, a planta apresenta regiões com crescimento secundário e possui região medular na raiz, com função de armazenamento de grãos de amido. As folhas exibem epiderme unisseriada, com tricomas glandulares, cutícula espessa e estômatos paracíticos, em ambas as faces. O mesofilo é dorsiventral, e a nervura central apresenta feixes vasculares colaterais com canais secretores associados ao floema. A caracterização histoquímica da folha evidenciou lipídios totais e compostos fenólicos, entre eles taninos e lignina, em diferentes tecidos da folha. A plântula apresenta características que demonstram sua adaptação ao ambiente Cerrado, como cutícula espessa, mesofilo dorsiventral, crescimento secundário e presença de tricomas, mesmo sendo cultivada em condições de viveiro.
\end{abstract}

Palavras-chave: Anatomia vegetal; Canais secretores; Cerrado.

\section{ANATOMICAL AND HISTOCHEMICAL CHARACTERIZATION OF ROOTS AND LEAVES OF Anacardium occidentale L. (Anacardiaceae) SEEDLINGS}

\begin{abstract}
Anacardium occidentale L. (Anacardiaceae) is a typical species of the Central Brazil cerrado and has socioeconomic importance. The present study aimed to characterize anatomically and histochemically the roots and leaves of this species at different stages of early development. For anatomical characterization, the samples were fixed in FAA ${ }_{50}$, embedded in paraffin and subjected to the usual procedures for light microscopy. Histochemical tests were performed to detect total lipids, tannins, lignin, starch and terpenoids with a carbonyl group in the leaves, and test for starch in roots in fresh cuts. The root has uniseriate epidermis, phloem and xylem with secretory ducts tetrarc. Five days after germination the plant presents regions with secondary growth and has the pith in the root, with storage function of starch grains. The leaves exhibit uniseriate epidermis with glandular trichomes, thick cuticle and paracytic stomata on both sides. The mesophyll is dorsiventral and midrib presents collateral vascular bundles with secretory ducts associated with phloem. The histochemical characterization showed lipids and phenolic compounds, including tannins and lignin in different tissues of the leaf. The seedling has characteristics that demonstrate its adaptation to Cerrado, as thick cuticle, dorsiventral mesophyll, secondary growth, presence of trichomes, even when cultivated in greenhouse.
\end{abstract}

Keywords: Plant anatomy; Secretory ducts; Cerrado.

\footnotetext{
${ }^{1}$ Recebido em 26.10.2012 aceito para publicação em 11.03.2014.

${ }^{2}$ Graduada em Ciências Biológicas, Universidade Federal do Tocantins, TO, Brasil. E-mail: <analuisa_lopes@hotmail.com>. ${ }^{3}$ Mestrado em Ecologia de Ecótonos, Universidade Federal do Tocantins, TO, Brasil. E-mail: <danyysouza@hotmail.com> e $<$ davibchagas@hotmail.com>.

${ }^{4}$ Graduação em Ciências Biológicas, Campus de Porto Nacional, Universidade Federal do Tocantins, TO, Brasil. E-mail:

$<$ lagares@uft.edu.br>.
} 


\section{INTRODUÇÃO}

O Estado do Tocantins encontra-se na zona de transição geográfica entre o Cerrado e a Floresta Amazônica, e o bioma Cerrado ocorre em quase todo o Estado, com predominância de vegetação xeromorfa aberta, dominada e marcada por estrato herbáceo (SILVA, 2007). Entre as diversas famílias presentes nessa região, pode-se destacar a família Anacardiaceae, sendo constituída por árvores ou arbustos que apresentam ductos resiníferos em seus ramos, frutos de sabor agradável, plantas produtoras de boa madeira ou de substâncias usadas na indústria e na medicina (BARROSO, 1991).

O gênero Anacardium pertence à família Anacardiaceae, possui a núcula como fruto verdadeiro, conhecido como "castanha-de-caju" (BARROSO, 1999). Entre as espécies deste gênero, encontra-se Anacardium occidentale L., objeto de estudo deste trabalho, que está distribuída nos Cerrados do Brasil Central, principalmente Goiás, Distrito Federal (PESSONI, 2007) e Tocantins. A espécie destaca-se pela importância alimentar, industrial, medicinal e econômica. É popularmente conhecida por cajuzinho-do-cerrado, cajuí ou caju-de-árvore-do-cerrado. Assim como $A$. occidentale, a grande maioria das espécies do Cerrado possui importância socioeconômica, além de sua importância biológica. No entanto, esse bioma é atualmente um dos mais ameaçados do país, pois grandes áreas vêm sendo ocupadas por extensas lavouras e pastagens, contribuindo para a sua descaracterização e degradação, o que coloca em risco sua biodiversidade (MARTINOTTO et al., 2008).

A anatomia de plântulas tem merecido atenção, já que o período de desenvolvimento inicial de uma planta é considerado crítico no ciclo de vida de muitas espécies, pois a plântula precisa de uma série de fatores ambientais propícios para se estabelecer (GURSKI, 2007). Esses trabalhos permitem a compreensão dos processos fisiológicos e estruturais das plântulas (MOURÃO et al., 2002), ampliam o conhecimento sobre determinada espécie ou grupamento sistemático dentro de um enfoque ecológico (LOPES; MATHEUS, 2008) e, ainda, relacionam as características das plântulas com as condições ambientais do local de ocorrência das espécies (IBARRAMANRÍQUEZ et al., 2001).

Associados à anatomia vegetal, os testes histoquímicos têm sido amplamente aplicados, sendo possível identificar compostos produzidos pelas plantas, o que pode ser feito o reconhecimento da natureza da secreção e dos locais de ocorrência nos tecidos da planta (FRANK-DE-CARVALHO; GRACIANORIBEIRO, 2005; SANT'ANNA-SANTOS et al., 2006; BARBOSA et al., 2007; VASCONCELOS-FILHO, 2008; SANTOS et al., 2009).

Este trabalho teve por objetivo caracterizar anatômica e histoquimicamente as raízes e folhas de plântulas de $A$. occidentale, em diferentes estádios de desenvolvimento, em condições de viveiro.

\section{MATERIAL E MÉTODOS}

Os frutos de $A$. occidentale foram coletados em uma área de Cerrado stricto sensu, localizada na Fazenda São Judas Tadeu, Município de Porto Nacional, Tocantins. Foram selecionadas 10 matrizes, sendo os frutos presentes no chão coletados de forma aleatória. Posteriormente, a parte comestível do fruto, chamada de pseudofruto, que consiste no desenvolvimento do pedúnculo em uma estrutura carnosa, foi retirada, e os frutos verdadeiros, conhecidos por castanha-de-caju, foram lavados em água corrente, colocados para secar e armazenados em vidros com tampa.

Foram selecionados aleatoriamente 30 frutos, sendo três de cada matriz. As sementes foram escarificadas mecanicamente em superfície abrasiva e semeadas a uma profundidade de $3 \mathrm{~cm}$ em sacos de polietileno de $17 \times 20 \mathrm{~cm}$, contendo como substrato solo de Cerrado e acomodados no viveiro de mudas do Núcleo de Estudos Ambientais (NEAMB) da Universidade Federal do Tocantins, com sombrite de $50 \%$ de sombreamento. As mudas foram irrigadas por sistema de irrigação por elevação (cano de PVC de $1 \mathrm{~m}$, com um aspersor na extremidade) duas vezes ao dia, com duração de 40 min cada irrigação.

A coleta das plântulas ocorreu no quinto, no décimo e no vigésimo dia após a germinação $(n=5)$, sendo consideradas germinadas aquelas sementes que tiveram a elevação da plúmula. As folhas foram coletadas no segundo nó, e a raiz foi seccionada nas zonas de crescimento, pilífera e de ramificação.

Para a microscopia de luz, as amostras foram fixadas em FAA $_{50}$ (formaldeído, ácido acético e álcool) e armazenadas em álcool etílico $70 \%$. Em seguida, parte das amostras foi desidratada em série etílica e infiltrada em parafina. No momento de emblocar, os fragmentos das folhas e raízes foram orientados seguindo o plano 
de corte (transversal, longitudinal e paradérmico para folha e transversal da raiz) e incluídos em parafina + cera de abelha $8 \%$. Os cortes foram feitos a $20 \mu \mathrm{m}$ de espessura, em micrótomo rotativo manual (Ancap), com navalha de aço descartável e aderidos à lâmina com adesivo de Haupt (1930). Os cortes foram desparafinizados em xilol e corados com safranina $1 \%$ e azul de Astra 1\% (GERLACH, 1984) e montados em bálsamo-do-canadá.

Para a caracterização histoquímica, foram utilizadas amostras frescas da porção mediana da folha e para as amostras radiciais, as zonas de crescimento, pilífera e de ramificação. As amostras foram seccionadas transversalmente em micrótomo de mesa (modelo LPC, Rolemberg e Hering LTDA.). Os testes histoquímicos na folha foram: Sudan III (JOHANSEN, 1940), para lipídios totais; 2,4-Dinitrofenil-hidrazina (GANTER; JOLLÉS, 1969), para terpenoides com grupo carbonila; vanilina clorídrica (MACE; HOWELL, 1974), para taninos; floroglucinol (JOHANSEN, 1940), para lignina; e lugol (JENSEN, 1962), para amido. As secções-controle foram realizadas simultaneamente, de acordo com as recomendações dos respectivos autores. Para o teste histoquímico da raiz, os cortes foram submetidos ao lugol (JENSEN, 1962), para detecção de amido.

As observações e a documentação fotográfica foram realizadas em microscópio de luz equipado com câmera (modelo KXD400G1, Diagtech LTDA.). As escalas referentes às ilustrações foram obtidas utilizando-se lâmina com escala micrométrica nas mesmas condições ópticas utilizadas em cada caso.

\section{RESULTADOS}

A raiz, em corte transversal, apresenta epiderme unisseriada, cuticularizada, com células em formato retangular (Figura 1A). É possível observar os pelos absorventes na epiderme conforme a região considerada (Figura 1B). O córtex parenquimático possui células de tamanhos variados e pouco espaço intercelular (Figura 1A, B). Na camada mais interna do córtex, encontra-se uma endoderme unisseriada com estrias de Caspary bem nítidas (Figura 1C). O cilindro vascular é delimitado por um periciclo unisseriado (Figura 1C). O xilema primário é um protostelo tetrarco (Figura 1C). O xilema apresenta-se de forma alternada ao floema, e este apresenta ductos secretores que são revestidos por células epiteliais secretoras (Figura 1F). É possível observar o estabelecimento do câmbio e do parênquima radial do xilema secundário, com cinco dias após a germinação, na região próxima ao ápice radical (Figura 1D), bem como a presença de uma medula parenquimática (Figura 1D, E). Também, foi possível observar raízes laterais (Figura 1D). O felogênio origina-se do parênquima cortical, e aos 20 dias após a germinação observa-se a presença de súber (Figura 1F).

A folha apresenta epiderme unisseriada com cutícula espessa e estômatos em ambas as faces (Figura 2A), possui de três a quatro camadas de colênquima angular, seguidas por células parenquimáticas com pouco espaço intercelular (Figura 2A, C). É constituída por três (Figura 2A, C) a cinco (Figura 2B) feixes vasculares do tipo colaterais com canais secretores associados ao floema.

O limbo apresenta epiderme unisseriada com cutícula espessa apresentando estômatos em ambas as faces, o que caracteriza uma folha anfiestomática (Figura 2D). O mesofilo é dorsiventral, constituído por um ou dois estratos de parênquima paliçádico de paredes delgadas com formato alongado e possui de quatro a cinco camadas de parênquima esponjoso de formatos variados. Feixes vasculares de pequeno diâmetro distribuem-se no mesofilo, circundados por uma bainha parenquimática. Canais secretores podem ser vistos associados ao floema nos feixes vasculares com uma bainha parenquimática ao seu redor (Figura 2D).

Em corte longitudinal da folha, é possível verificar os ductos secretores associados ao floema (Figura 2E). Em corte paradérmico do limbo foliar, as células da epiderme apresentam paredes anticlinais sinuosas e estômatos do tipo paracíticos, em ambas as faces (Figura 2F). É possível observar tricomas do tipo glandular na epiderme (Figura 2F, G), formados por uma célula na base e 12 células na cabeça secretora.

As plântulas com cinco dias de idade apresentaram poucos grãos de amido na medula (Figura 3A). O teste histoquímico para amido aplicado na raiz reagiu positivamente na medula parenquimática das plântulas (Figura 3B). Na caracterização histoquímica da folha, verificou-se reação positiva para amido apenas nas células parenquimáticas (Figura 3C). O teste para lignina foi positivo na parede das células do xilema (Figura 3D). A reação positiva para lipídios totais evidenciou a presença de cutícula espessa na epiderme da folha (Figura 3E), comprovado pelo teste-controle (Figura $3 \mathrm{~F}$ ). O teste para taninos

Revista Árvore, Viçosa-MG, v.38, n.2, p.209-219, 2014 


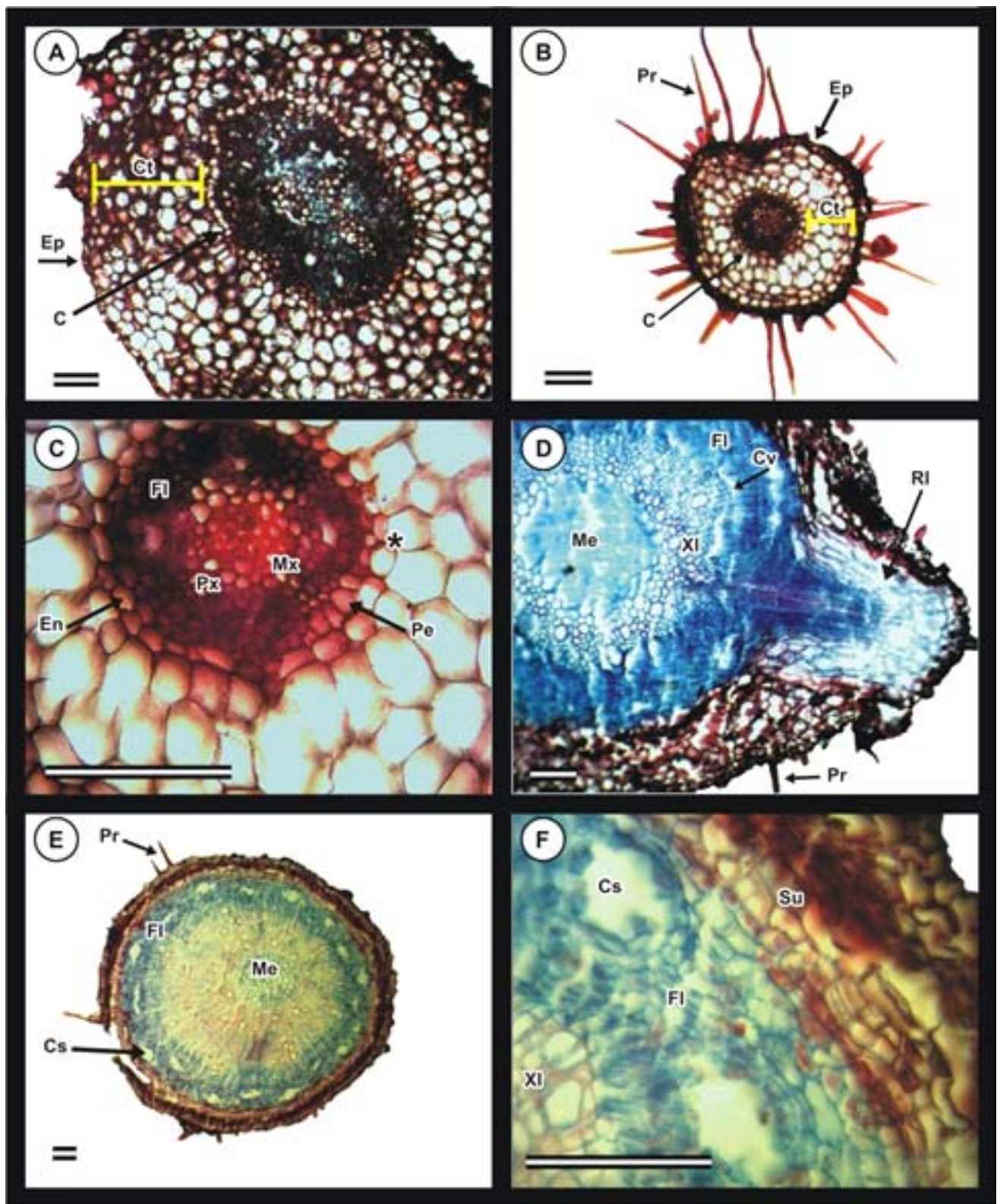

Figura 1-Cortes transversais da raiz de Anacardium occidentale: A. cinco dias após a germinação. B. 10 dias após a germinação. C. Detalhe do cilindro vascular, estrias de Caspary $(*)$. D. Corte da região de ramificação com presença de medula parenquimática. E. 20 dias após a germinação. F. Detalhe do súber; C (cilindro vascular); Cs (canal secretor); $\mathrm{Ct}$ (córtex parenquimático); Cv (câmbio vascular); En (endoderme); Ep (epiderme); Es (epitélio secretor); F1 (floema); $\mathrm{Me}$ (medula parenquimática); Mx (metaxilema); Pe (periciclo); Pr (pelo radicular); Px (protoxilema); R1 (raiz lateral); S (Súber); e Xi (Xilema). Barra $=100 \mu \mathrm{m}$.

Figure 1 - Transverse sections of the root of Anacardium occidentale. A. five days after germination. B. 10 days after germination. C. Detail of the vascular cylinder Casparian (*). D. Cut the branch region with presence of parenchymatous pith. E. 20 days after germination. F. Details of suber. C (vascular cylinder); Cs (secretory channel); Ct (parenchymatous cortex); Cv (vascular cambium), En (endoderm), Ep (epidermis); Es (secretory epithelium); Fl (phloem); Me (marrow parenchyma); Mx (metaxylem); Pe (pericycle); Pr (root hair); Px (protoxylem); Rl (root side); S (suber); and Xi (Xylem). Bar $=100 \mu \mathrm{m}$.

Revista Árvore, Viçosa-MG, v.38, n.2, p.209-219, 2014 


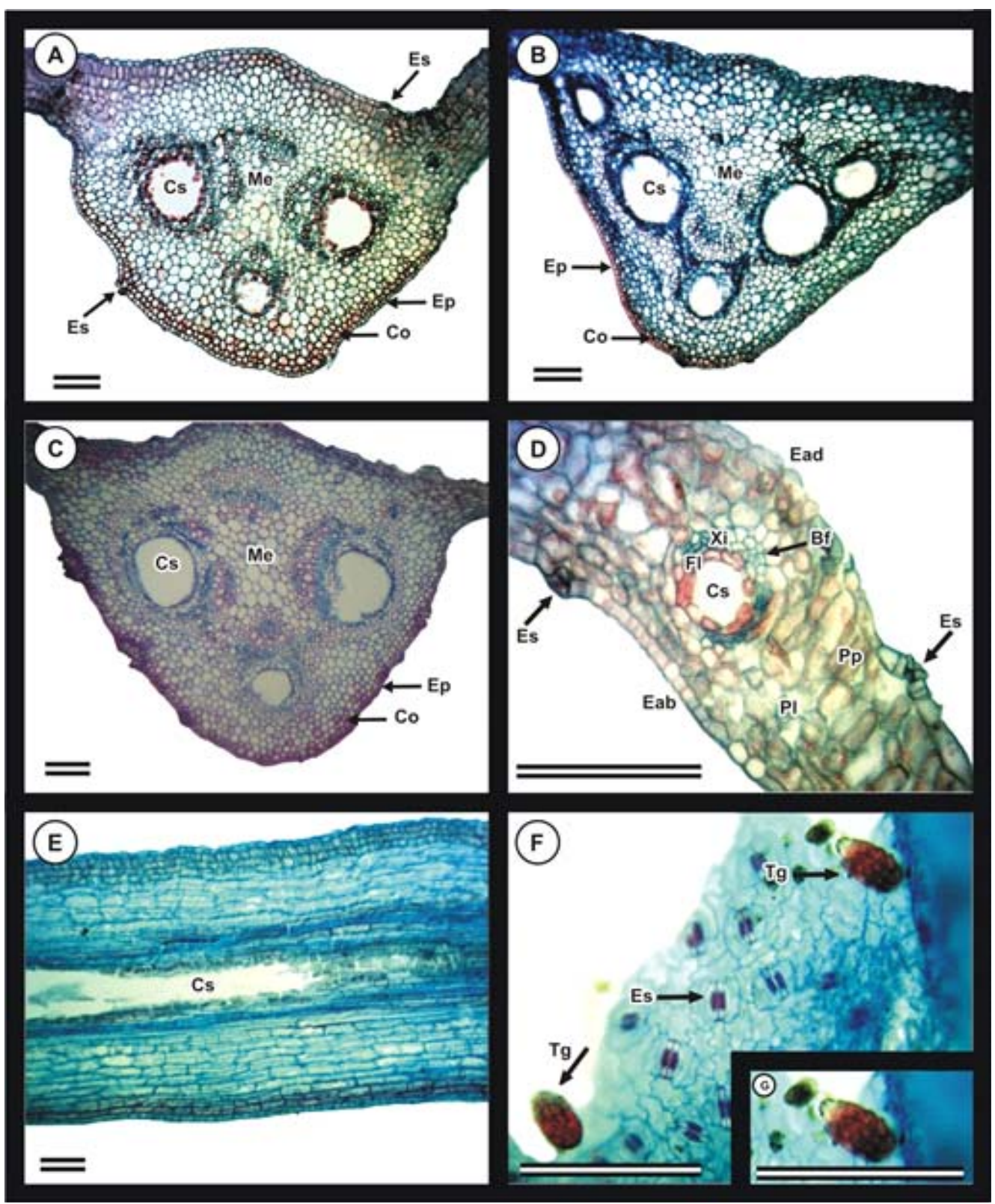

Figura 2 - Cortes transversais da folha da plântula de Anacardium occidentale: A. Nervura central cinco dias após a germinação. B. nervura central 10 dias após a germinação. C. nervura central 20 dias após a germinação. D. Mesofilo. E. Corte longitudinal evidenciando o canal secretor. F. Corte paradérmico evidenciando tricomas glandulares. G. Detalhe do tricoma. Bf (bainha do feixe); Co (colênquima); Cs (canal secretor); Eab (face abaxial); Ead (face adaxial); Ep (epiderme); Es (estômato); Me (medula parenquimática); Pl (parênquima esponjoso); Pp (parênquima paliçádico); e Tg (tricoma glandular). Barra $=100 \mu \mathrm{m}$.

Figure 2 - Transverse sections of the seedling leaf of Anacardium occidentale. Midrib A. five days after germination. B. 10 days after germination. C. 20 days after germination. D. Mesophyll. E. Longitudinal section showing the secretory channel. F. Paradermic cut showing glandular trichomes. G. Detail of trichomes. Bf (bundle sheath); Co (collenchyma); Cs (secretory channel); EAB (abaxial); Ead (adaxial epidermis); Ep (epidermis); Es (stomata), Me (parenchyma pith); Pl (spongy parenchyma); Pp (palisade parenchyma); and Tg (glandular trichomes). Bar = $100 \mu \mathrm{m}$. 


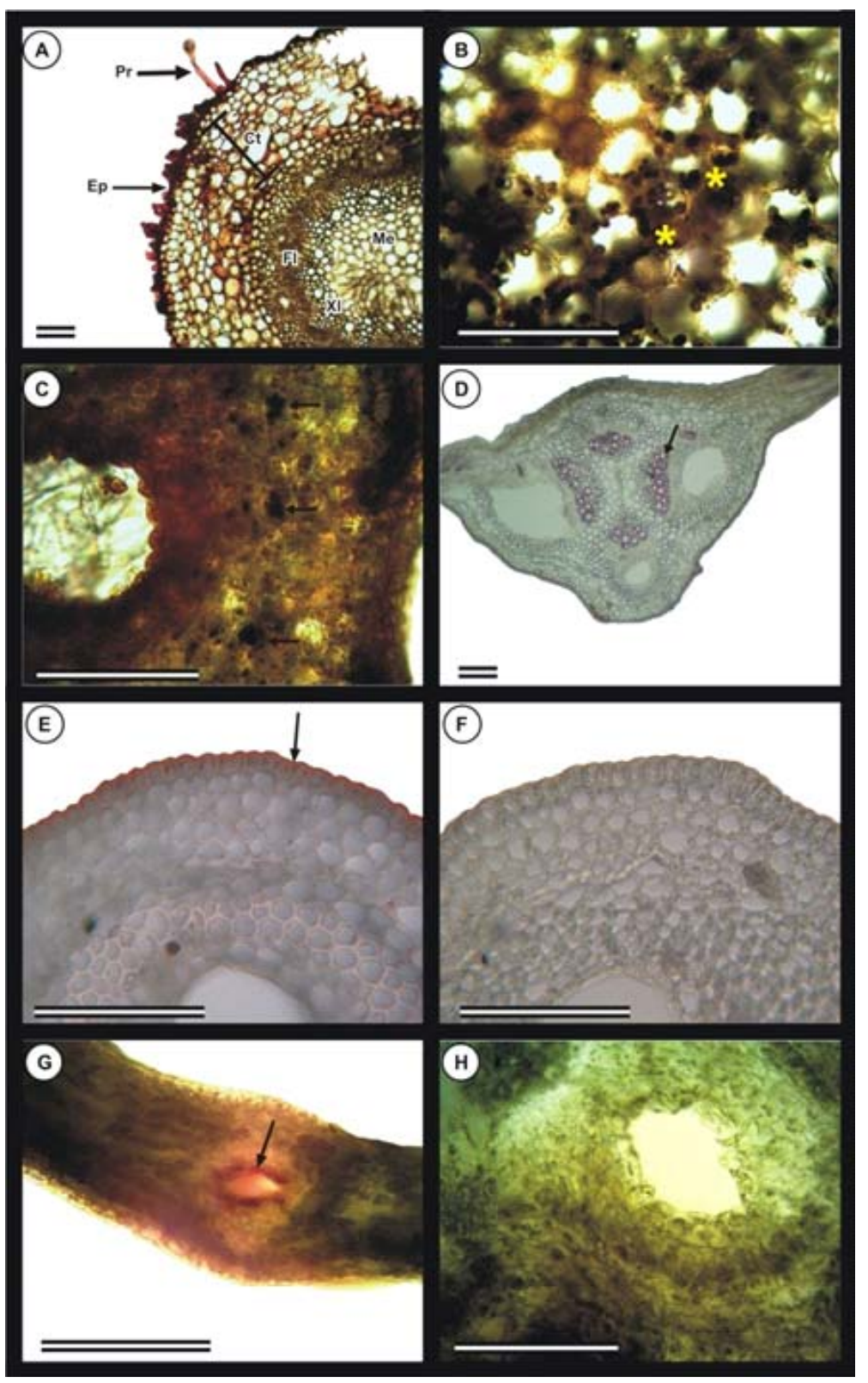

Figura 3 - Caracterização histoquímica da plântula de Anacardium occidentale. Cortes transversais. A. Reação negativa para amido na raiz de cinco dias após a germinação. B. Reação positiva para amido na medula parenquimática da raiz com 10 dias após a germinação. C. Reação positiva para amido nas células parenquimáticas do mesofilo (setas). D. Reação positiva para lignina (seta). E. Reação positiva ao Sudam III (seta). F. Controle. G. Reação positiva para taninos (seta). H. Controle - Grão de amido (*). Ct (córtex parenquimático); Ep (epiderme); F1 (floema); Me (medula parenquimática); $\operatorname{Pr}$ (pelo radicular); e Xl (xilema). Barra $=100 \mu \mathrm{m}$.

Figure 3 - Histochemical characterization of Anacardium occidentale seedlings. Transverse sections. A. Negative reaction to starch in the root five days after germination. B. Positive reaction to starch in the root parenchyma in the root medulla 10 days after germination. C. Positive reaction to starch in parenchymal cells of the mesophyll (arrows). D. Positive reaction for lignin (arrow). E. Positive reaction to Sudam III (arrow). F. Control. G. Positive reaction for tannin (arrow). H. Control. Starch grain (*). Ct (parenchyma cortex); Ep (epidermis); Fl (phloem); Me (parenchyma pith); $\operatorname{Pr}$ (root hair); and Xl (xylem). Bar = $100 \mu \mathrm{m}$.

Revista Árvore, Viçosa-MG, v.38, n.2, p.209-219, 2014 
reagiu positivamente nas células do epitélio secretor e mesofilo (Figura 3G), o que pode ser confirmado pelo teste- controle (Figura $3 \mathrm{H}$ ).

\section{DISCUSSÃO}

A presença de ductos secretores nos órgãos vegetativos nas plântulas de $A$. occidentale confirma essa característica marcante da família Anacardiaceae (METCALFE; CHALK, 1957; BARROSO, 1991; PELL, 2004). O corte longitudinal da folha permite afirmar que as estruturas secretoras são ductos por apresentarem lume alongado, diferentemente das cavidades ou bolsas que possuem lume isodiamétrico. Estudos de desenvolvimento desses canais em outras espécies da família Anacardiaceae relataram que esses canais são originados a partir de células procambiais, a partir de divisões em diferentes planos celulares, resultando em células de tamanhos variados, e o lume tem origem a partir de afastamento e degeneração de células epiteliais (LACCHIA; CARMELLO-GUERREIRO, 2009).

Nas raízes das plântulas de $A$. occidentale, foi observado o início de crescimento secundário com cinco dias após a germinação na região mais próxima ao ápice radical. Esse fato pode ser considerado característica da espécie que, mesmo no cultivo em viveiro, apresentou essa característica. Aos 20 dias após a germinação, o felogênio já estava estabelecido, e já foi observado o início de formação do súber, estando ainda a epiderme presente. A periderme está relacionada não só com a idade do órgão, mas, também, com as condições ambientais, fornecendo proteção à planta contra temperaturas extremas provocadas, por exemplo, por fogo (AOYAMA; MAZZONI-VIVEIROS, 2006).

A presença de medula parenquimática na região do cilindro vascular pode indicar uma região de transição entre raiz e caule (SOUZA; OLIVEIRA, 2004; ORTOLONI et al., 2008), já que esse tecido não é típico de raiz de Eudicotiledônea e, sim, de caule. No entanto, $A$. occidentale apresentou medula no centro do cilindro vascular da raiz, inclusive em secções onde foi possível observar raízes laterais, ou seja, abaixo da zona de transição. Além disso, o teste histoquímico foi positivo para amido na raiz, evidenciando a presença de um tecido de reserva nutritiva nessa região. Estudos comparativos em raízes de plantas presentes em regiões com amido, apenas nas raízes de plantas oriundas da região do Cerrado típico, e isso pode ser uma resposta adaptativa ao ambiente (SANTOS, 2012).
A maioria das plantas armazena amido como carboidrato de reserva (VIJN; SMEEKENS, 1999), e em $A$. occidentale esse acúmulo de carboidrato pode estar relacionado não só como fonte de energia, mas também com a tolerância aos estresses ambientais do Cerrado, como secas prolongadas e queimadas, sendo, portanto, estratégia adaptativa da espécie às condições adversas do ambiente, uma vez que o desenvolvimento de estruturas de reserva, nas raízes, contribui para a sobrevivência de plântulas do Cerrado (FRANCO, 2008). A ocorrência de sistemas subterrâneos de reserva de carboidratos foi relatada por Tertuliano e FigueiredoRibeiro (1993) em espécies de Asteraceae do Cerrado, também como resposta adaptativa ao ambiente que se desenvolve.

Aos cinco dias após a germinação, as folhas de A. occidentale apresentam cutícula espessa recobrindo a epiderme, evidenciada pelo teste com Sudan III. Essa característica, embora tenha sido relatada não ser característica confiável para xeromorfia (CUTLER et al., 2011), funciona como barreira à perda excessiva de água, evitando a dessecação (TAIZ; ZEIGER, 2004). Cutículas espessas também foram observadas em outras espécies de Cerrado, como Anemopaegma arvense, Zeyheria montana e Jacaranda decurrens pertencentes à família Bignoniaceae (MAURO et al., 2007), Himatanthus obovatus (Apocynaceae) (CARMO et al., 2005) e em Richterago hatschbachii (Asteraceae) (MELO-DE-PINNA, 2004).

Estudos que relacionam o tipo de mesofilo às condições ambientais demonstram que, mesmo em grupos taxonomicamente distintos, existe correlação entre a distribuição de espécies e a anatomia de órgãos fotossintéticos (BURROWS, 2001). As plântulas de A. occidentale analisadas neste trabalho exibiram ocorrência de mesofilo dorsiventral, e isso pode estar relacionado ao seu ambiente de origem.

A característica anfiestomática da folha de $A$. occidentale também tem sido considerada como estratégia de plantas a ambiente muito seco ou sob incidência solar intensa, maximizando a condutância estomática, já que trocas gasosas serão realizadas pelas duas faces da folha (MOTT et al., 1982) e, com isso, a planta aproveita melhor o pouco tempo de alta umidade relativa a esses ambientes (MEDRI; LLERAS, 1980). O fato de terem sido observados neste trabalho estômatos na face abaxial também é característica da espécie que mostra sua adaptação ao ambiente natural (DICKISON, 2000). A

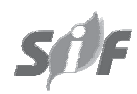

Revista Árvore, Viçosa-MG, v.38, n.2, p.209-219, 2014 
observação de estômatos paracíticos na espécie em estudo foi coincidente com outras espécies do Cerrado pertencentes ao gênero Forsteronia, mas nessas plantas os estômatos estão restritos à face abaxial da epiderme (RIO, 2006). No entanto, em estudo da anatomia foliar de espécies adultas de Anacardium excelsum e Anacardium occidentale, Martinez-Millián e CevallosFerriz (2005) observaram estômatos anomocíticos apenas na face abaxial.

A ocorrência de tricomas na superfície foliar também pode atuar como estratégia adaptativa em $\mathrm{A}$. occidentale, já que podem desempenhar importante função contra a perda d'água, além de refletir o excesso de luz solar, permitindo à planta absorver somente a luminosidade necessária para as suas atividades vitais (LARCHER, 2004). Essa adaptação foi igualmente descrita para Zeyheria montan (MAURO et al., 2007) e S. lycocarpum (ELIAS et al., 2003), ambas as espécies do Cerrado. Martínez-Millán e Cevallos-Ferriz (2005) descreveram os tricomas glandulares de Anacardiaceae formados geralmente por um pedúnculo, que pode ser unicelular ou pluricelular e com uma cabeça geralmente pluricelular e multisseriada, cilíndrica, ovoide ou cônica. Os tricomas observados nas folhas das plântulas em foco neste trabalho se assemelham aos descritos por MartínezMillán e Cevallos-Ferriz (2005) para a família. Entretanto, esses autores não observaram tricomas em $A$. occidentale e atribuíram esse resultado ao fato de que as formas imaturas são mais pubescentes e de que durante a expansão foliar muitos tricomas simplesmente caem. No entanto, tanto Torres e Jáuregui (1999) quanto Roth e Lindorf (2002) observaram a presença de tricomas glandulares em $A$. occidentale.

Foi observada uma bainha parenquimática em volta do canal secretor do mesofilo, o que, segundo Machado e Carmello-Guerreiro (2001), produz novas células epiteliais, possibilitando a renovação de células e a manutenção da atividade secretora durante o desenvolvimento do órgão.

Foram detectadas substâncias lipofílicas e hidrofílicas na folha, evidenciando lipídios e compostos fenólicos, respectivamente. Esses dados corroboram os descritos na família Anacardiaceae, com diversas espécies que produzem vários compostos do metabolismo secundário que podem ser usados tanto na medicina quanto na defesa e adaptação das plantas ao ambiente (PELL, 2004).

Revista Árvore, Viçosa-MG, v.38, n.2, p.209-219, 2014
Na região do mesofilo no parênquima clorofiliano e nas células do epitélio do canal secretor de $A$. occidentale, foi possível observar acúmulo de tanino, um tipo de composto fenólico. A presença desses compostos pode ser uma característica da própria espécie que se desenvolve naturalmente, pois, mesmo no cultivo em viveiro, ela apresentou essa característica. Substâncias fenólicas também foram descritas em abundância nas folhas de Gomphrena arborescens L. f., espécie nativa do Cerrado (FRANK-DE-CARVALHO; GRACIANORIBEIRO, 2005). Segundo Joly (2005), muitas anacardiáceas produzem tanino, utilizado na indústria dos curtumes.

Embora os testes para detecção de compostos fenólicos no lume do canal tenham dado resultados negativos, não se pode concluir, de modo absoluto, que esses compostos não existem no secretado, uma vez que os testes para fenólicos são, de modo geral, pouco específicos, havendo compostos que, na maioria das vezes, só são detectáveis em microscopia de fluorescência em luz ultravioleta, devido à sua grande labilidade (SANT'ANNASANTOS et al., 2006).

Os compostos depositados no lume dos ductos secretores de $A$. occidentale não reagiram para nenhum dos testes aplicados. De acordo com Sant'Anna-Santos et al. (2006), a detecção de secretados exclusivamente no epitélio ou no lume, bem como sua ocorrência em menor proporção nesses sítios, pode ser indicativo de eventos cíclicos de secreção. Em ultraestrutura caulinar de Anacardium occidentale, ocorre grande número de vesículas no citoplasma das células do epitélio secretor em alguns ductos e menor ocorrência em outros, o que seria indício da existência de fases distintas de secreção (NAIR et al., 1983).

\section{CONCLUSÃO}

Os resultados de $A$. occidentale confirmaram caracteres pertinentes à família Anacardiaceae como canais secretores associados ao floema, canais secretores associados aos feixes vasculares na nervura central e tricomas glandulares pluricelulares.

Os dados confirmaram que a espécie apresentou caracteres típicos de plantas que estão sob restrição hídrica, como: cutícula espessa, parênquima 
paliçádico bem desenvolvido, mesofilo dorsiventral, tricomas, substâncias fenólicas e tecido de reserva nutritiva, mesmo sendo cultivada em viveiro com irrigação diária.

\section{REFERÊNCIAS}

AOYAMA, E. M.; MAZZONI-VIVEIROS, S. C. Adaptações estruturais das plantas ao ambiente. São Paulo: Instituto de Botânica, 2006.

BARBOSA, J. S.; SOUSA, H. C.; RIBEIRO, S. P. Estudo morfológico, anatômico e fenológico de três populações de Lychnophora ericoides (Asteraceae) em áreas de campo rupestre: respostas locais e diferenciação na produção de compostos bioativos. In: CONGRESSO DE ECOLOGIA DO BRASIL, 8., Caxambu, MG, 2007. Anais...Disponível em $<$ http://www.sebecologia.org.br/viiiceb/pdf/1022.pdf $>$ acesso em 06 de dez. 2011.

BARROSO, G. M. Sistemática de angiospermas do Brasil. Viçosa, MG: Universidade Federal de Viçosa, 1991. v.2. 377p.

BARROSO, G. M. et al. Frutos e sementes: morfologia aplicada à sistemática de dicotiledôneas. Viçosa, MG: Universidade Federal de Viçosa, 1999. 443p

BURROWS, G. E. Comparative anatomy of the photosynthetic organs of 39 xeromorphic species from subhumid new South Wales, Australia. International Journal of Plant Sciences, v.162, n.2, p.411-430, 2001.

CARMO, E. J. S. et al. Caracterização anatômica de folhas adultas de Himatanthus obovatus (M.Arg.) Wood (Apocynaceae). In: SEMINÁRIO DE INICIAÇÃO CIENTÍFICA (SIC-UEG).

Universidade Estadual de Goiás, 2005. Disponível em $<$ http://www.prp.ueg.br/06v1/conteudo/ pesquisa/inic-cien/eventos/sic2005/arquivos/ biologicas/caracterizacao anatomica.pdf $>$ acesso em: 10 de dez. 2011.

CUTLER, D. F.; BOTHA. T.; STEVENSON, D. W. Anatomia vegetal - uma abordagem aplicada. Porto Alegre: Artmed, 2011.304p

DICKISON, W. C. Integrative plant anatomy. Orlando: Harcourt/Academic Press, 2000. 455p.
ELIAS, S. R. M. et al. Anatomia foliar em plantas jovens de Solanum lycocarpum A.St.-Hil. (Solanaceae). Revista Brasileira de Botânica, v.26, n.2, p.169-174, 2003.

FAHN, A. Plant anatomy. 4.ed. Oxford: Pergamon Press, 1990. 588p.

MAURO, C. et al. Estudo anatômico das espécies de cerradoAnemopaegma arvense (Vell.) Stellf. ex de Souza (catuaba), Zeyheria montana Mart. (bolsa-de-pastor) e Jacaranda decurrens Chamisso (caroba) Bignoniaceae. Revista Brasileira de Farmacognosia, v. 17, p. 262-265, 2007.

FANK-DE-CARVALHO, S.M.; GRACIANORIBEIRO, D. Arquitetura, anatomia e histoquímica das folhas de Gomphrena arborescens L.f. (Amaranthaceae). Acta Botanica Brasilica, v.19, n.2, p.377-390, 2005.

FRANCO, A.C. Relações hídricas em plantas do Cerrado: as plantas lenhosas do cerrado respiram livremente? In: PRADO, C.H.B.A.; CASALI, C.A. Fisiologia vegetal: práticas em relações hídricas, fotossíntese e nutrição mineral. Barueri: Manole, 2008.

GANTER, P.; JOLLÉS, G. Histologie normale et pathologique. Paris: Gauthier - Villars, 1969. v.1. 1904p.

GERLACH, D. Botanische

Mikrotechnik:Eine Einführung.

Sttutgart: Georg Thieme Verlag, 1984. 311p.

GURSKI, C. Estudos comparativos de plântulas e plantas jovens de duas espécies de Ormosia Jackson provenientes de ambientes distintos restinga e mata ciliar. 2007. $76 \mathrm{f}$. Dissertação (Mestrado em Biologia Vegetal) Universidade Federal de Mato Grosso do Sul Mato Grosso do Sul, 2007.

IBARRA-MANRÍQUEZ, G.; RAMOS, M. M.; OYAMA, K. Seedling functional types in a lowland rain forest in Mexico. American Journal of Botany, v.88, n.10, p.1801-1812, 2001.

HAUPT, A. W. A gelatin fixative for paraffin sections. Stain Technology, v.5, p.97-98, 1930.

Revista Árvore, Viçosa-MG, v.38, n.2, p.209-219, 2014 
JENSEN, W. A. Botanical histochemistry. San Francisco: WF Freeman and Co, 1962. 408p.

JOHANSEN, D. A. Plant microtechnique. New York: McGraw-Hill, 1940. 523p.

JOLY, A. B. Botânica: introdução a taxonomia vegetal. São Paulo: Companhia Nacional, 2005. $777 \mathrm{p}$.

KRAUS, J. E.; ARDUIN, M. Manual básico de métodos em morfologia vegetal. Seropédica: EDUR, 1997. 198p.

LACCHIAA. P. S.; CARMELLO-GUERREIRO, S. M. Aspectos ultra estruturais dos canais secretores em órgãos vegetativos e reprodutivos de Anacardiaceae. Acta Botanica Brasilica, v.23, n.2, p.376-378, 2009.

LARCHER, W. Ecofisiologia vegetal. São Carlos: Rima, 2004. 531p.

Lista de Espécies da Flora do Brasil 2013 in http://floradobrasil.jbrj.gov.br/ acessado em 10-04-2013.

LOPES, J. C.; MATHEUS, M. T. Caracterização morfológica de sementes, plântulas e da germinação de Dimorphandra wilsonii Rizz. faveiro-de-wilson (fabaceae-caesalpinioideae). Revista Brasileira de Sementes, v.30, n.1, p.96-101, 2008.

MACE, M. E.; HOWELL, C. R. Histochemistry and identification of condensed tannin precursor in roots of cotton seedlings. Canadian Journal of Botany, v.52, p.2423-2426, 1974.

MACHADO, S. R.; CARMELLO-GUERREIRO, S. M. Estrutura e desenvolvimento de canais secretores em frutos de Schinus terebinthifolius Raddi (Anacardiaceae).

Acta Botânica Brasílica, v.15, n.2, p.189-195, 2001

MARTINEZ-MILLIÁN, M.; CEVALLOS-FERRIZ, S. R. S. Arquitectura foliar de Anacardiaceae. Revista Mexicana de Biodiversidade, v.76, n.2, p.137-190, 2005.

MARTINOTTO, C. et al. Cagaiteira (Eugenia dysenterica DC.). Lavras: Universidade Federal de Lavras, 2008. 21p. (Boletim Técnico, 78).

Revista Árvore, Viçosa-MG, v.38, n.2, p.209-219, 2014
MAURO, C. et al. Estudo anatômico das espécies de cerrado Anemopaegma arvense (Vell.) Stellf. ex de Souza (catuaba), Zeyheria montana Mart. (bolsa-de-pastor) e Jacaranda decurrens Chamisso (caroba) - Bignoniaceae. Revista Brasileira de Farmacognosia, v.17, n.2, p.262-265, 2007.

MEDRI, M. E.; LLERAS, E. Aspectos da anatomia ecológica de folhas de Hevea brasiliensis Müell. Arg. Acta Amazônica, v.10, n.3, p.463-493, 1980.

MELO-DE-PINNA, G. F. A. Anatomia foliar de Richterago Kuntze (Mutisieae, Asteraceae). Acta Botânica Brasílica, v.18, n.3, p.591-600, 2004.

MEtCAlfe, C. R.; CHALK, L. Anatomy of the dicotyledons.Oxford: Claredon Press, 1957. 724p.

MOTT, K. A.; GIBSON, A.C.; O’LEARY, J.E. The adaptative significance of amphistomatic leaves. Plant Cell and Environment, v.5, n.6, p.455-460, 1982 .

MOURÃO, K. S. M. et al. Morfo-anatomia da plântula e do tirodendro de Trichilia catigua A. Juss., T. elegans A. Juss. e T. pallida Sw. (Meliaceae). Acta Scientiarum, v.24, n.2, p.601-610, 2002.

NAIR, G. M.; VENKAIAH, K.; SHAH, J. J. Ultrastructure of gum-resin ducts in Cashew (Anacardium occidentale). Annals of Botany, v.51, p.297-305, 1983.

ORTOLONI, F. A. et al. Morfo-anatomia de plântulas e número cromossômico de Cybistax antisyphilitica (Mart.) Mart. (Bignoniaceae). Acta Botanica Brasilica, v.22, n.2, p.345-353, 2008.

PELL, S. K. Molecular systematics of the cashew family (Anacardiaceae). 2004. 193f. Tese (Doutorado em Filosofia) - Department of Biological Sciences, Faculty of the Louisiana State University, Louisiana, 2004.

PESSONI, L. A. Estratégia de análise da diversidade em germoplasma de cajueiro (Anacardium spp. L.). 2007. 159 f. Tese (Doutorado em Genética e Melhoramento) Universidade Federal de Viçosa, Viçosa, MG, 2007. 
RIO, M. C. S. Estudos anatômicos em espécies de Forsteronia G.Mey.

(Apocynaceae) de cerrado. 2006. $201 \mathrm{f}$. Tese (Doutorado em Biologia Vegetal) -

Universidade Estadual de Campinas, Campinas São Paulo, 2006.

ROTH, I \& Lindorf, H. South American medicinal plants. Botany, remedial properties and general use. Springer, Heidelberg. 2002. 492 p.

SANT'ANNA-SANTOS, B. F. et al. Anatomia e histoquímica das estruturas secretoras do caule de Spondias dulcis Forst. F. (Anacardiaceae). Revista Árvore, v.30, n.3, p.481-489, 2006.

SANTOS, M. C. A. et al. Anatomia e histoquímica de folhas e raízes de vinca (Catharanthus roseus (L.) G. Don). Revista de Biologia e Ciências da Terra, v.9, n.1, p.24-30, 2009.

SANTOS, K. D. G. Germinação e desenvolvimento inicial de Dipteryx alata VOGEL e Parkia platycephala BENTH (FABACEAE) sob condições de campo. 2012. 49f. (Dissertação de Mestrado em Ecologia de Ecótonos)- Universidade Federal do Tocantins, 2012.

SILVA, L. A. G. C. Biomas presentes no Estado de Tocantins. Brasília: Consultoria Legislativa, 2007. (Nota técnica)
SOUZA, L. A.; OLIVEIRA, J. H. G. Morfologia e anatomia das plântulas de Tabebuia avellanedae Lor. ex Griseb e T. chrysotricha (Mart. ex Dc.) Standl. (Bignoniaceae). Acta Scientiarum, v.26, n.2, p.217-226, 2004.

TAIZ, L.; ZEIGER, E. Fisiologia vegetal. 3.ed. Porto Alegre: Artmed, 2004. 719p

TERTULIANO, M. F.; FIGUEIREDO-RIBEIRO, R. C. L. Distribution of fructose polymers in herbaceous species of Asteraceae from the cerrado. New Phytology, v.123, p.741-749, 1993.

TORRES, M.; JAUREGUI, D., The foliar anatomy of four species of fruit trees Anacardium occidentale; Mangifera indica; Spondias purpúrea and Psidium guajava. Ennstia, v.9, n.3/4,1999.

VASCONCELOS-FILHO, S. C. Caracterização anatômica e histoquímica de folhas, calogênese e fitoquímica de calos de murici [Byrsonima verbascifolia (L.)

Rich. Ex. Jus]. 2008. 70f. Dissertação (Mestrado em Botânica) - Universidade Federal de Viçosa, 2008.

VIJN, I.; SMEEKENS, S. Fructan: More than a reserve carbohydrate? Plant Physiology, v.120, p.351-359, 1999. 
